in consequence of the length of time the solution bad remained in it undisturbed, supplied data for an estimation of the quantity of the fatal duse. The former, amounting to half a drachm, converted into sulphide was found to represent exactly a decigramme, or rather more than one grain and a half of arsenious acid, and, the total quantity of liquid in the bottle being nine drachms, would equal twentysêven grains and three-quarters. Deducting from this total the quantity left in the buttle, the conclusion is reached that upwards of twenty-six grains had been swallowed. The fatal period is one of the shortest on record, indeed I am aware of only one instance in which a more rapidly fatal result ensued. This occurred in the case of a youth aged seventeen, who was stated to have died within twenty minutes after a large dose, the symptoms being of a tetanic character. Reference is made to it in Taylor's "Principles and Practice of Medical Jurisprudence," vol."i., page 256, second edition, but details are wanting. In the present case the largeness of the dose, its state in solution, and the comparatively empty condition of the stomacb, all of which would favour rapid absorption, sufficiently account for the speedy death. The same considerations also account for the somewhat abnormal character of the symptoms, those referable to the stomach being slightly marked, while collapse was profound and conspicuous. Such cases lend support to the opinions expressed by M. Vryens, whose experiments and the conclusions drawn therefrom are set forth in the "Archives de Pbysiologie," vol. viii., 1881. The latter are to the effect that the fuudamental character of arsenical poisoning consists in a perversion of the entire nervous system, and that the pneumogastric, sympathetic, and vaso-motor nerves especially are paralysed or reduced to a state of paresis.

Montagu-street, $\mathbf{w}$.

\section{CASE OF PRESUMED RUPTURE OF THE BLADDER.}

BY T. F. HUGH SMITH, F.R.C.S. ENG.

ON Sept. 17th J. F__, a healthy-looking man, aged thirty-two, fell from the saddle whilst riding over stone paring, "all of a heap," and the horse's off hind leg is said to have struck him in the abdomen. The man had drunk beer freely during the day, and had not passed water since 11 A.M. The accident happened at 4.30 P.M. Vomiting occurred immediately; also abdominal pain was experienced, which "doubled him up." He asked to have his clothes loosened on account of a feeling of tightness round the abdomen. The patient was seen for the first time at 10 P. M. No urine had been passed, though there was strong desire and constant straining made. He felt pain in the abdomen, most marked in the upper two-thirds. The thighs were flexed, the patient lying on his right side. The extremities were below normal temperature; pulse full (6t). Resonance was general over the abdomen. A No. 8 catheter was passed easily up to the "eyes ;" two ounces and a balf of urine mixed with altered blood were drawn off. Heat to the extremities and hot fomentations to the abdomen were applied, and a pill containing one grain of opium was ordered to be given every three hours. A catheter was tied in, and a little urine welled up when the patient made any effort.-18th: The patient dozed during last night; took beef-tea and milk, together with a teaspoonful of brandy, every three hours. At 4.15 P.M. a soft catheter à coudée (No. 10) was substituted for No. 8, silver. The heat of the extremities returned to normal. Paroxysms of abdominal pain occurred at intervals of a few minutes. - 19th: The patient had a sleepless night on account of abdominal pain. With the exception of slightly increased pain and a rise of temperature to $101^{\circ}$, the patient did well until the 21st.-21st: The catheter was blocked at 2 A.M. ; some urine found its way alongside of the instrument. When seen at $6 \mathrm{~A} . \mathrm{M}$, there were symptoms of collapse. Temperature $98^{\prime} 1^{\circ}$; pulse 120 . Great pain in, and tenderness of, abdomen. Opium increased. A larger gum elastic catheter was tied in ; urine, deep crimson, containing some mucus. Tympanites and distension; vomited at 3 P. M. ; stimulants increased. 6 P.M. : Pain began to abate; urine passed through catheter. - 22nd: Very little pain during the night. Catheter acting well. Pulse 108. 4 P.M. : General condition favourable; enema given and returned; on removing catheter for cleausing clear urine tlowed frecly per urethram. Pulse 116 ; tempera ure $103^{\circ}$. Catheter left out for the first time since the accident (sixth day). 5.30 P.M. : Vomiting.-23rd: Bilions vomitıng frequent; pulse tull, jerky $(96)$; temperatule $99^{\circ}$. One pint of water passed during the night per urethram; four ounces came away on passing catheter. Catheter again tied in. 5.30 P.M. : Severe ab. dominal pain ; enema given and returned with flatus; some relief, but distension remained.-24th : Evident emaciation, anxious countenance; upper two-thirds of abdomen prominent and tympanitic, lower third appeared to be bound down, and marked dulness detected in the left flauk. The patient passed four pints of clear acid urine during the past twenty.four hours. Vomiting continued, and he gradually sank, dying at 7 A.M., September 26th.

Remarks.-There were three periods of interest in the case-first, that of reaction followed by progress (September $18 \mathrm{~L}, 19 \mathrm{th}, 20 \mathrm{~h})$; secondly, that of collapse when the catheter became blocked (September 2lst); thirdly, that of greatly increased peritonitis following soon upon omission of catheter on the afternoon of September 22nd. The omission of the catheter was made against the advice of $m y$ father, Mr. Henry Smith, and of my senior partner, Dr Ashurst, but the passage of clear urine per urethram on the 22 nd, occurring after my having sought that advice, together with the risk of blocking the catheter (the patient living at a distance of three miles), induced me to trust to expulsion through the natural passage on the sixth day after the presumed rupture. No post-mortem was made.

Farningham.

\section{CASE OF ADYNAMIC RHEUMATIC FEVER RESEMBLING SEPTICAEMIA,}

WITH SECONDARY PLECRO. PNEUMONIA OF LOW TYPE.

\section{By R. A. D. LITHGOW, LL.D , M.R.C.P.ED.}

CASES of acute or subacute rheumatism, running an erratic course, and characterised by many symptoms of septicæmia, are always interesting from a clinical point of view ; and their comparative infrequency leads me to hope that the following notes of a case which occurred in my practice may be deemed worthy of record.

J. B-, aged twenty-nine, a draper's assistant, whom I had attended a few weeks previously for slight catarrhal sore-throat, sent for me on January 13th, when he was suffering from an inflamed foot, which he attributed to gout He was pale and unhealthy looking, fairly muscular, but flabby, of nervous temperament, and, so far as I could ascertain, of steady habits. He had had an attack of rheumatic fever when seventeen years of age which confined him to bed for several weeks, and in January, 188l, had suffered from a less acute attack of a similar character. His family history was satisfactory, except in the case of his father, who had died at the age of fifty-two from cancer of the stomach. I found him suffering from rheumatic inflam. mation of the foot, principally affecting the joint of the great toe, but with little or no symptomatic disturbance; and he complained of having "pains shooting about him." The heart was somewhat weak, but healthy as to size, sounds, and rhythm, and there was no albumen in his urine, which was, however, loaded with lithates. I prescribed suitable regimen, an alkaline mixture, and hot fomentations to the foot. He expressed himself as feeling better next day, but I was struck with his unhealthy-looking appearance. The local swelling and pain had considerably subsided, but he experienced "flying pains all over." Pulse, temperature, and respiration normal; has had no rigor, but feels weak.-January 15th: $I$ found the patient confined to bed with all his middle joints affected with rheumatism, but of an erratic, subacute character. Pulse 120, temperature $100 \cdot 2^{\circ}$; furred tongue, profuse characteristic acid perspirations; respiration normal ; chest clear; sleepless and fidgety; urine loaded with lithates. I ordered the joints to be wrapped in cotton-wool and prescribed the following mixture : fifteen grains of salicylate of soda with solution of acetate of ammonia every four hours, and ten grains of compound ipecacuanha powder at bedtime. Diet to consist of beet-tea, sodawater-and-milk, barleywater, \&c Gave cautious prognosis - - 16th: Pulse 120 temperature $100.8^{\circ}$; pains relieved, but flying from one 
joint to another and back; chent unaffected; water very biuhlcoloured, and passes it only twire in tweuty-four hours, and then with some difficulty ; bowels costive, relieved by medicine; no albumen; seens wenk, and had slight delirium during the night. The salicylates evidently disagreeiug with him, I returned to the former alkaline treatment, and ordered bicarbonate of potash in twenty-grain doses. Explained the serious character of his condition to his friends.-18th: Pulse 124; temperature $1012^{\circ}$, Pains abating, but continue to fly from one joint to another; general coudition unaltered; slightly delirious at night, and generally restless; complained of pain in front of the left chest, but the stethoscope revealed nothing abnormal; heart's action feeble, but healthy ; præcordial area normal; respiration unaffected and satisfactory. -19 th : Pulse 120; temperature $1018^{\circ}$; less delirium at night, and passes water much more freely since medicine was altered; pains still subacute and erratic, but less severe; bowels costive, relieved by medicines; no rigors or albumen; otherwise much the same. -20th: Pulse 120; temperature $101^{\prime} 8^{\circ}$; condition unaltered; slight effusion in knees and ankles. Treatment to be continued.-21st: Has had a sleepless night, with considerable delirium, talking about business, \&c. The rheumatic pains are no longer a prominent symptom, but he complains of stiffoess in all his joints; tongue browner, and less moist; no rigor; respiration more frequent; pulse 130; temperature $1022^{\circ}$; chest, shoulders, neck, \&c., covered with a copious crop of sudamina, of an iuteresting and remarkable character, almost resembling a pu-tular eruption. Discovered fine crepitant râles in basic lubules of both lungs; careful examination of the heart revealed nothing whatever abnormal ; does not feel worse in himself, but complains of increased weakness. Ordered poultices to the chest, and to continue the same general treatment, with the addition of a dessertspoonful of brandy every four hours. As I had all along formed an unfavourable prognosis of the case, I arranged for Dr. Sansom to see him to-morrow. $-22 n d$ : Pulse 132 ; temperature $102 \cdot 8^{\circ}$; nocturnal delirium; crepitant râles over an increased area, with fine pleuritic friction-sounds at each base. Dr. Sansom saw the patient with me, and having examined him very carefally, concurred with my diagnosis and treatment, and gave a very unhopeful opinion as to the termination of the case. Patient expreses himself as better, but feels his breathing more difficult. Sudamina very profuse, but unaltered in character or extent; tongue moist, but slightly brown; bowels costive; case throughout characterised by asthenia. Dr. Sansom suggested the administration of quinine with the alkali, in the form of a powder, to be given in water every four hours, and the brandy to be continued. General treatment unaltered; skin to be sponged with warm water and sulphate of soda.-23rd, 10 A.M. : Bowels had been relieved twice naturally. Pulse 132 , temperature $103^{\circ}$. Very restless night, with low muttering delirium and occasional paroxysms of excitement; slight pain in right ankle, knee, and wrist; skin moist; sudainina disappearing; respiration 38; crepitant area increased, but patchy ; pleuritic symptoms unaltered; no pain in chest; general condition Vrry un:ati-factory; patient evidently losing strength.23rd, 5 P.M. : Pulse 140 ; temperature $1048^{\circ}$; delirium in creasing; talks about business, \&c., when he dozes; restless and fidgety; respiration and chest symptoms generally unchanged; slight pain in several joints, all of which are stiff. Nervous system more deeply involved; patient eager, restless, and excited; slight choreiform symptoms; tongue moist, and patient takes fluid nourishment freely ; anxious, piached look on face; no albumen; general condition worse decided to try cold sponging to-morrow. $-24 \mathrm{th}, 330 \mathrm{~A}$. M. Died rather suddenly; delirium increased from $10 \mathrm{P}$. M. last night to $1 \mathrm{~A} . \mathrm{M}$ this morning, when he was very exclted, and could scarcely be kept in bed. Became calmer afier $1 \mathrm{~A}$ M., and gradually merged into unconsciousness, in which state he passed away quietly about $3.30 \mathrm{~A} . \mathrm{M}$.

Remarks. - There are two especial points of interest in connexion with this case to which I would here briefly allude -viz., the resemblance of many of the symptoms to seuticæmia, and the peculiarities of the vesicular eruption which was developed during the second week. In its general aspect the case seemed to be one of those comparatively rare forms of rheumatic fever which closely resemble septicaera; but, in the absence of any obvious source of blood poisoning, it is difficult to account tor its production. The slight sorethroat, for which the patient had come to me once or twice some three or four weeks previous to his last illness, might at first seem to indicate the probable seat of infection, and some analogy might thus be found to post-scarlatinal rheumari.m ; but as the condition of the throat was merely that of slight local congestion, continuing for a day or two, without any discoverable abrasion of the surface, and unattended by any pyrexial symptoms, I think the throat affection and the sy mptoms of septicæmia-developed after an interval of a month-cannot be regarded as having had any special relationship. Be this as it may, and however obscure the source of blood-poisoning may have been, there can be no doubt that in this case some other toxic element was developed in addition to that of rheumatism, the real point of iuterest being whether the rheumatico-arthritic affection was merely one of the symptoms of a heterogeneous septicæmic con. dition, or whether an adventitious septic agent had developed itself in the course of an adynamic ty pe of rheumatic fever occurring in a weak subject. As the result of considerable experience, I feel assured that where rheumatism of a low erratic type occurs in asthenic subjects there is almost invariably the gravest cause for apprehension. The miliary or sudaminal rash was very prolific and remarkable, the chest, neck, and shoulders, especially on their anterior aspect, being completely covered, so that not a point of unaffected skin could be seen between the vesicles. The eruption had appeared almost suddenly, having become fully developed during one night, and was so virulent and copious that at first sight it seemed like a well-defined outburst of confluent pustules. Closer examination, however, revealed its true character as a vesicular rash undoubtedly due to profuse acid diaphoresis. The vesicles themselves were pearly, with more or less turbidity of contents, but without any marginal redness of their bases, such as is frequently seen in the so-called true miliary form. Varying in size, and somewhat irregular in form, although the larger ones were principally hemispherical, all the vesicles were distinctly elevated above the skin, and the continuity, extent, and development of the eruption were such as I have certainly never before seen under similar circumstances. I may just add that the eruption began to fade after about thirty-six hours, and that, concurrently with the rash on chest, \&c., sparse patches of a similar character appeared on the limbs and trunk.

Walton-place, S.W.

ON

\section{NITRITE OF SODIUM IN THE TREATMENT \\ OF EPILEPSY AND AS A TOXIC AGENT.}

BY A. H. BAINES, M.R.C.S., L.R.C.P. LoND., HONORARY SURGEON TO THE SOUTHPORT INFIRMARY.

I HAVE a twofold object in writing this paper : one, to show the undoubted efficacy of nitrite of sodium in the treatment of epilepsy', at least in the single case of a patient of mine; and the other, to suggest that medical men, in giving this drug, in whatsoever disease, should first ascertain whether it is a pure specimen or adulterated with nitrate of sodium; for if, as hitherto usually supplied to the profession, it is largely contaminated with this latter salt, comparatively large doses, as a scruple, will be required to produce the desired effect; whereas, if the drug is quite or nearly pure, one or two such doses might prove fatal, or, at any rate, bring about alarming symptoms. The salt I prescribed in the following case, though obtained from a firstclass firm of manufacturing druggists, must have been far from pure, at least for the first few weeks of its administration, and until the untoward symptoms, which I shall relate, were produced, when presumably it was prepared in a purer form, was therefore stronger, and, from the large doses administered, beyan to act in a poisonous manner. This hypothesis has weight lent to it from the fact that upon inquiry I found the undesirable symptoms were developed at the time that the drug was being dispensed from the first part of a vew supply of it, the former supply having lasted perhaps seven or eight weeks. It is not unlikely that during this time, owing to a demand for greater purity in the drug, it became possesped of greater power; this condition beloning to it when it acted unfavourably. Of course this is ouly conjecture, but un'ess it has a basis of truth in it, it compels me to fall back on the only other hypothesis which I can thiok of-namely, that the drug is cumula. 